\title{
From Embodied and Extended Mind to No Mind
}

\author{
Vincent C. Müller \\ Anatolia College/ACT, Pylaia, Greece \& \\ Programme on the Impacts of Future Technology, University of Oxford, UK \\ vmueller@act.edu \\ www.sophia.de
}

\begin{abstract}
The paper will discuss the extended mind thesis with a view to the notions of "agent" and of "mind", while helping to clarify the relation between "embodiment" and the "extended mind". I will suggest that the extended mind thesis constitutes a reductio ad absurdum of the notion of 'mind'; the consequence of the extended mind debate should be to drop the notion of the mind altogether - rather than entering the discussion how extended it is.
\end{abstract}

\section{The Standard View}

The standard view is that self-contained agents pursue their own goals, sometime in cooperation with other agents, and sometimes using external tools. This typically, but not necessarily, goes together with a view of these agents as rational agents that perceive, then plan and finally act; and the view that robots should be built that way: with sensors, processor and effectors (this view of agents through internal cognitive states, rather than behavioral dispositions, is what I would call 'cognitivism'). This view, in turn goes together with the view that humans and other natural cognitive agents are computational information processors made up of several modules that take in symbolic representations of the world, process these according to specified rules and then produce a symbolic output (this view I call 'computationalism'). In philosophy, cognitivism and computationalism are often take to be scientific explanations of the traditional view that humans have a mind and mental states, and that these states partially explain human behavior. Even those that reject either one or both of these explanations tend to maintain that the traditional view of the mind is largely correct (the Churchlands are a notable exception).

I will suggest that all of the traditional view above is false, but I will argue only for the falsity of the first statement, about self-contained agents and the last, about humans having minds.

\section{Embodiment}

The rejections of some of the traditional theses take various forms and there is a rather confusing landscape of options. However, one point of criticism is that the traditional view - in distancing itself from its original opponent, behaviorism - puts undue 
emphasis on a central processing notion of cognition, it talks rather as if cognition was something that I, the agent, do from within my body, taking the information from my sensory system as input, processing this and producing output in the form of actions (typically movements). This image, which has first been properly developed by René Descartes talks as though there were a little man, a homunculus, inside me watching a theatre play - what Dennett aptly called the 'Cartesian theatre' [1]. “... it is a mistake to believe that the brain has any deeper headquarters, any inner sanctum arrival at which is the necessary or sufficient condition for conscious experience." [2]. But not only is there no little man inside me and cognition cannot fruitfully be explained by this model, but the model seems inconsistent, even: The little man would seem to need yet another little man to watch what he is doing, etc. - or, in a different terminology, the information would have to be 'encoded' in some way, which results in a need for further decoding of the decoding [3].

Instead of this image, we need to take in many of the cognitive features of the agent that only come into existence due to the interaction with the environment. Also, it seems that any symbols in the cognitive systems need to have "grounding" [4] in physical interaction with the world, in order to be meaningful for the system. The cognitive system is thus embodied in the sense of a "dynamical interaction (coupling) of an embodied system that is embedded in the surrounding environment", "it never goes completely formal" [5]

The rejections of cognitivism and the rejection of computationalism are often lumped into one, presumably because a rejection of cognitivism is thought to imply a rejection of computationalism - but this might not be true (certainly not for pancomputationalists) and the inverse is clearly not true. Descartes was not a computationalist, but he surely was a cognitivist.

In my view, the thesis that "cognition is embodied" takes three main forms, which in turn have their variations:

1. Embodiment as an empirical thesis. For example:

- Sensation and experience require movement (e.g. of eyes or percept), so perception is a kind of action [6][7] and we should really speak of a "sensorimotor system" rater than "sensory system"

- Conscious experience is action experience [8]

2. Embodiment as an engineering thesis. For example:

- Many tasks can be achieved by active control or by body morphology (e.g. running) [9]

- Body involvement is a design choice (e.g. active sensing) ... [10]

3. Embodiment as a metaphysical thesis. For example

- There can be no disembodied homunculus inside watching a 'Cartesian theatre'

- There can be no meaningful symbols in a cognitive system without embodiment and embeddedness 
I think it will become clear shortly that the extended mind thesis is first and foremost a metaphysical thesis, which then has an empirical consequence (the human mind is often extended) and an engineering consequence (it does not matter where you locate the resources for a cognitive function).

\section{$3 \quad$ Extended Mind}

Andy Clark and David Chalmers [11] have proposed the much-discussed thesis that cognitive processes of humans can and do take place outside the head; in particular that artifacts we use, like notebooks or electronic devices are part of our cognitive apparatus. We are thus, in Clark's words "Natural Born Cyborgs" [12] with "Supersized Minds" [13]. I will introduce the 'extended mind' thesis and try to find out which consequences we should draw from the discussion - in particular for the notion of the cognitive 'agent' and for the 'embodiment' of agents.

Clark and Chalmers show a number of examples where it does not seem to matter whether the human cognitive activity takes places 'in the head' or outside: rotating blocks mentally or physically (to see whether they would fit a gap in the computer game 'Tetris'), touching something with hands or a stick, counting in the head vs. with fingers and, finally, Inga and Otto who have the belief that "The Museum of Modern Art is on $53^{\text {rd }}$ Street". Since beliefs are still the staple 'mental state' for most philosophers, this example in [11] has produced the most debate.

Inga knows there the museum is because she remembers it, quite normally. Otto also knows where the museum is, but he has Alzheimer's Disease and thus keeps such information in a notebook that he can consult. If you find the idea of the notebook to 'external', imagine that Otto has a brain implant that functions as his notebook. Also note, that we quite naturally say such things as "I know what time it is" (because I have a watch) or "I believe I have an appointment" (my computer says so).

So, what we have is extended mental processes (like mental rotation), extended perception and extended belief - in short, the extended mind.

The main line of the extended mind thesis is often summarized in what Clark calls a Parity Principle:

If, as we confront some task, a part of the world functions as a process which, were it done in the head, we would have no hesitation in recognizing as part of a cognitive process, then that part of the world is (so we claim) part of the cognitive process. [11][cf. 13]

This principle is meant to overcome the traditional image which is " $\ldots$ in the grip of a simple prejudice: the prejudice that whatever matters about mind must depend solely on what goes on inside the biological skin-bag, inside the ancient fortress of skin and skull." [14]. Instead, we should accept that "non-biological resources, if hooked appropriately into processes running in the human brain, can form parts of larger circuits that count as genuinely cognitive in their own right" [15] It does not matter 
that these processes are not biological and it does not matter how they are hooked into the processes - using perceptual apparatus (as in the notebook) is just as acceptable as a more direct brain interface. What matters is that they are intuitively mental, in particular they function as such. So, the extended mind thesis is that mental processes do not only take place inside the skull or skin.

\section{Conclusion}

If we consider the full picture of 'cognition', we can not restrict ourselves to what is 'inside the skin', we must allow for cooperation, even intelligence of complex wholes (like 'swarms'), for cognitive offloading onto the environment and culture [16], for construction of our own cognitive niche [17][13] and we must remember that much of the abilities of agents are due to the morphology of their bodies [9]. This does not mean, however, that we must conclude that 'the mind is extended' - because that becomes absurd - but that we must forget about describing the abilities of such agents and systems in terms of 'minds' and their location.

Instead, we must admit that out perspectives and explanatory purposes determine where we want to make the 'cut' of what counts as 'one agent' - and then the best explanation wins, whether it involves only systems inside a skin or not. The notion that is left is the "person" - which we need for ethics (but it has no sharp boundaries and is dependent on purposes). What we must do is to forget about 'the mind' instead, ask 'how does this work? In other words: The proof is in the pudding. It is time to change perspective: The mind is dead.

\section{References}

1. Dennett, D.C.: Consciousness Explained. Little, Brown \& Co., New York (1991)

2. Dennett, D.C., Kinsbourne, M.: Time and the Observer: The Where and When of Consciousness in the Brain. Behavioral and Brain Sciences 15, 183-247 (1992)

3. Bickhard, M.H.: Representational Content in Humans and Machines. Journal of Experimental and Theoretical Artificial Intelligence 5, 285-333 (1993)

4. Harnad, S.: The Symbol Grounding Problem. Physica D 42, 335-346 (1990)

5. Calvo, P., Gomila, T. (eds.): Handbook of Cognitive Science: An Embodied Approach. Elsevier, München (2008)

6. Noë, A.: Action in Perception. MIT Press, Cambridge (2005)

7. Myin, E., O'Regan, K.J.: Studied Perception and Sensation in Vision and Other Modalities: A Sensormotor Approach (2006)

8. O'Regan, K.J.: Why Red Doesn't Sound Like a Bell: Understanding the Feel of Consciousness. Oxford University Press, New York (2011)

9. Pfeifer, R., Bongard, J.: How the Body Shapes the Way We Think: A New View of Intelligence. MIT Press, Cambridge (2007)

10. Cangelosi, A., Riga, T.: An Embodied Model for Sensorimotor Grounding and Grounding Transfer: Experiments with Epigenetic Robots. Cognitive Science 30(4), 673-689 (2006)

11. Clark, A., Chalmers, D.J.: The Extended Mind. Analysis 58(1), 7-19 (1998) 
12. Clark, A.: Natural Born Cyborgs: Minds, Technologies, and the Future of Human Intelligence. Oxford University Press, Oxford (2003)

13. Clark, A.: Supersizing the Mind: Embodiment, Action, and Cognitive Extension. Oxford University Press, New York (2008)

14. Clark, A.: Natural Born Cyborgs? Edge (December 28, 2000), http: / / www . edge . org

15. Clark, A.: Letter on Fodor on 'Where Is My Mind? London Review of Books 31(6) (March 26, 2009)

16. Hutchins, E.: Enculturating the Supersized Mind. Philosophical Studies 152(3), 437-446 (2011)

17. Clark, A.: Language, Embodiment, and the Cognitive Niche. Trends in Cognitive Sciences 10(8), 370-374 (2006) 